\title{
The perspectives of patients and physicians on the role of pharmacists in improving medication adherence in type 2 diabetes: a qualitative study
}

This article was published in the following Dove Press journal: Patient Preference and Adherence

\section{Zahra Alsairafi \\ Mohammad Waheedi (iD \\ Fatemah Alsaleh \\ Department of Pharmacy Practice, Kuwait University, Faculty of Pharmacy, Hawalli, Kuwait}

Background: Pharmacy practice has been expanded to include responsibility for the outcomes of medication therapy. However, in developing countries the pharmacist's role is still limited to dispensing medications. The aim of this study is to explore the perspectives of patients and physicians on the pharmacist's role in improving medication adherence in type 2 diabetes.

Methods: Data were collected via semi-structured interviews with patients and physicians. The interviews were audio-recorded, transcribed verbatim and analysed using thematic analysis.

Results: A total of 40 patients and 21 physicians were interviewed. The interviews revealed different pharmacy-related issues that negatively affected patients' adherence, such as a lack of pharmacist counselling and inappropriate scheduling of refills. Various recommendations to improve adherence were emphasised such as dedicating some pharmacists to counselling patients and providing pharmacists with the appropriate training.

Conclusion: From the perspectives of patients and physicians, the pharmacist's role in the management of type 2 diabetes is still limited to dispensing medications. In order to improve medication adherence and consequently patient outcomes, policy-makers need to be aware of the importance of supporting pharmacists and providing them with the appropriate training. Keywords: medication adherence, type 2 diabetes, qualitative, perspectives of patients/ healthcare providers

\section{Introduction}

Diabetes is a global public health concern. In the Middle East, it is one of the most rapidly growing non-communicable diseases. ${ }^{1}$ The estimated prevalence of diabetes in Kuwait is $23.3 \%$. Specifically, the incidence of type 2 diabetes has increased dramatically over the past decades. ${ }^{1}$ Patients with diabetes have healthcare expenditures that are ten times higher than they would be in the absence of diabetes. ${ }^{2}$ In Kuwait, the majority of patients $(60 \%)$ who manage their type 2 diabetes with insulin in hospitals cannot achieve the glycaemic targets of glycated haemoglobin (HbA1c) levels of less than $7 \% .^{3}$ At the primary care level, $19 \%$ of patients with type 2 diabetes have poor HbA1c levels. ${ }^{4}$ Recently, it has been reported that the rate of medication non-adherence among adults with type 2 diabetes is $44 \%{ }^{3}$

Healthcare reforms that are based on patient-centredness have involved a move towards multidisciplinary teams of health professionals from different disciplines who work together to care for patients. In the twenty-first century, the pharmacy profession is moving towards a new approach, patient-centred care, which constitutes the pharmaceutical care process. ${ }^{5}$ It has been demonstrated that pharmaceutical care
Correspondence: Mohammad Waheed PO Box 24923, Safat, Hawalli 13110, Kuwait

Tel +96566223629

Email mohdw@hsc.edu.kw 
programmes delivered by pharmacists result in significant improvements in glucose and $\mathrm{HbAlc}$ levels and dramatic reductions in the costs of inpatient hospitalisation and emergency department services. ${ }^{6}$ The public healthcare system in Kuwait is divided into primary, secondary and tertiary care. Primary care is delivered through general and specialised polyclinics around five healthcare regions. Secondary care is provided through six general hospitals, and tertiary care is delivered through fifteen specialised centres. ${ }^{7}$ The pathway of patients with type 2 diabetes starts when the patient is first diagnosed with the disease in a primary care clinic. After the management of their disease is instituted, controlled patients continue their follow-ups in the polyclinics. Uncontrolled patients are referred to secondary care hospitals to follow up with specialists. Physicians are responsible for prescribing medications for patients. Medications are dispensed by pharmacists and collected from pharmacies by patients.

There is one Faculty of Pharmacy in Kuwait, established in 1997, providing a 5-year bachelor degree and a 2-year add-on PharmD programme. Since 2002, approximately 30-40 students have graduated every year. Clinical pharmacy is included as a part of the curriculum with a focus on medication therapy management. Unfortunately, in practice, the pharmacist's role in Kuwait is still limited to dispensing medications, preparing formulations and performing some administrative tasks such as ordering medications from the Medical Stores. Clinical pharmacy activities are limited and only based on individual pharmacists' initiatives with no or little support from the Ministry of Health (MOH). In Kuwait, pharmacists are not included in patients' care and only some of them, who have a passion for clinical services, provide patient education; they do not have the authority to prescribe medications. ${ }^{8}$ It has been reported that patients' inaccurate knowledge of diabetes and its complications, their disbelief in the necessity of medications, and the lack of a multidisciplinary approach in the healthcare system of Kuwait are contributors to medication non-adherence in type 2 diabetes. ${ }^{9}$ This highlights a critical area for improvement within clinical pharmacy, particularly in the management of chronic diseases such as type 2 diabetes.

\section{Aim}

Patients are becoming ever more educated and empowered, and it is essential to explore their experiences. Patients who are satisfied with their healthcare providers have better satisfaction with the care provided and better medication adherence. ${ }^{10}$ In addition, studies providing the perspectives of physicians on the role of pharmacists, particularly in regards to medication adherence in the Middle East, are lacking. ${ }^{11}$ Therefore, the aim of this study was to elicit the views and experiences of patients and primary care physicians concerning the pharmacist's role in improving medication adherence, particularly in type 2 diabetes.

\section{Methods}

\section{Study design and population}

Cross-sectional semi-structured interviews were conducted. Semi-structured interviews allowed the participants to discuss the issues freely and highlight their recommendations. This provided a deeper understanding of the participants' views and experiences surrounding the role of pharmacists in improving medication adherence than could have been obtained with other tools, such as questionnaires.

The study was performed in Kuwait, a Middle Eastern country with an area of $17,820 \mathrm{~km}^{2}$ and an approximate population of $3,065,850$ individuals (2011 estimate). ${ }^{12}$ It was conducted during the period from July to December 2017. The study concerns both primary care and hospital pharmacists. Thus, this study's population comprised physicians working in primary care clinics and adults with type 2 diabetes who are treated in secondary care hospitals.

Although two studies ${ }^{13,14}$ have previously been conducted among pharmacists in Kuwait to describe their role in diabetes management, obtaining the perceptions of other people who are involved in diabetic care may bring out various views and experiences and highlight the differences between the perspectives of people who are involved in the care process. Pharmacist self-reporting of their competence may not accurately reflect their actual competence. Participants may be biased with a wish towards providing socially desirable responses. ${ }^{15}$

In this study, collecting data via semi-structured interviews meant the most valuable data were obtained; patients were asked open questions that allowed them to explain their perceptions and enabled the researcher to further explore the responses. This flexibility would not have been achieved if the study had employed structured interviews, which lack the flexibility in two-way communication between the interviewer and the interviewee. Employing unstructured interviews would not have ensured the covering of topics of interest to all participants. ${ }^{16}$ 


\section{Instrument development}

Two interview topic guides were developed specifically to achieve the study's aim. Review of the literature ${ }^{9}$ assisted in structuring the schedules and designing some of the questions. The interviews comprised open questions, and prompts were added to encourage participants to provide rich information. Leading questions were avoided, to prevent the introduction of bias. In addition, the topic guides were flexible; more questions were added during the interviews as participants raised issues of concern. Therefore, the researchers followed and expanded on arising issues to ensure that all relevant views and experiences were obtained. The topic guides were revised by the research team, comments regarding the contents and structure were incorporated and the final versions were agreed by all.

The patients' topic guide included eight questions concerning the use of medications during daily life, and views and experiences surrounding the role of pharmacists in the management of type 2 diabetes, particularly in regard to promoting the proper use of medications and the support needed from pharmacists to improve medication adherence. The physicians' topic guide included five questions focusing on how physicians perceive the role of pharmacists in the management of type 2 diabetes and the support needed from pharmacists in addressing non-adherence of patients. At the end of the interviews, the discussion was clearly concluded by asking the following question: "Finally, is there anything else about the role of pharmacists that you want to talk to me about?" The complete interview topic guides can be found in Tables $\mathrm{S} 1$ and $\underline{\mathrm{S}} 2$.

\section{Sampling strategy and recruitment}

All adults (age $\geq 18$ years) with type 2 diabetes who used medications and were treated in the main six hospitals in Kuwait (Mobarak Al-Kabeer, Al Amiri, Al Adan, Al Farwaniya, Al Jahra and Al Sabah) were eligible to participate in this study. Accordingly, all eligible adults who visited outpatient clinics during the data collection period were invited to participate. The exclusion criteria were not consenting to participate and having type 1 diabetes. 70 patients were approached. All of them responded directly (response rate 100\%), of whom 40 agreed to participate and were subsequently interviewed (participation rate 57\%), while 30 refused to participate. (Reasons for non-participation are shown in Table 1.)

Patients were approached by the principal investigator as they attended their appointments with consultants. The researcher arrived at the clinic early in the morning, before patients' appointments commenced, and checked the patients list with the clinic nurse, identifying patients who met the eligibility criteria from their medical notes. The patients were then approached in the waiting area. The time and place for conducting the interview were arranged with those who agreed to take part (Table 2 shows the characteristics of the participants.) Because the time and place of the interview were agreed based on the participant's convenience and preference, each patient's interview was completed in the hospital where he/she was being treated. Interviews were conducted either in the waiting area, where the researcher had a private desk placed in a corner at a great distance from other patients, or in a nurse room that was unoccupied specifically for this purpose. However, one participant preferred to be interviewed in the hospital cafeteria. The interview was not conducted during the busiest times of day, which meant the interview was conducted with minimal distractions. In addition, careful attention was given to ensure no one was around who might observe or influence the flow of the interviews. The duration of the patients' interviews was 20-30 mins.

Physicians involved in the care of patients with type 2 diabetes were also invited to participate in this study. A

Table I Reasons for non-participating in the patients' interviews $(n=30)$

\begin{tabular}{|l|l|}
\hline Reason & Number of patients giving that reason \\
\hline Having pending housework & 8 \\
Not having a car and being unable to attend based on the driving person's schedule & 5 \\
Having other hospital appointments & 7 \\
Feeling unwell due to age, disability, tiredness, social circumstances & 6 \\
Needing to go back to work & $\mathrm{I}$ \\
Having other commitments e.g. collecting grandchildren/children from school & $\mathrm{I}$ \\
Travelling & $\mathrm{I}$ \\
No reason given & $\mathrm{I}$ \\
\hline
\end{tabular}


Table 2 Characteristics of the participating patients $(n=40)$

\begin{tabular}{|c|c|}
\hline Variables & $\begin{array}{l}\text { Summary statistics } \\
\mathbf{N}(\%)\end{array}$ \\
\hline \multicolumn{2}{|l|}{ Age, years } \\
\hline Mean (SD) & $55.2(13.9)$ \\
\hline $18-30$ & $2(5)$ \\
\hline $31-50$ & $12(30)$ \\
\hline $51-70$ & $22(55)$ \\
\hline$>70$ & $4(10)$ \\
\hline \multicolumn{2}{|l|}{ Sex } \\
\hline Male & $10(25)$ \\
\hline Female & $30(75)$ \\
\hline \multicolumn{2}{|l|}{ Ethnicity } \\
\hline White & $37(92.5)$ \\
\hline Non-white & $3(7.5)$ \\
\hline \multicolumn{2}{|l|}{ Nationality } \\
\hline Kuwaiti & $34(85)$ \\
\hline Non-Kuwaiti & $6(15)$ \\
\hline \multicolumn{2}{|l|}{ Marital Status } \\
\hline Unmarried/divorced/widowed & $7(17.5)$ \\
\hline Married & $33(82.5)$ \\
\hline \multicolumn{2}{|l|}{ Employment } \\
\hline Employed & $12(30)$ \\
\hline Retired & $13(32.5)$ \\
\hline Housewife & $15(37.5)$ \\
\hline \multicolumn{2}{|l|}{ Education } \\
\hline Cannot read and write & $3(7.5)$ \\
\hline Primary school & $10(25)$ \\
\hline Secondary school & $5(12.5)$ \\
\hline Diploma & $8(20)$ \\
\hline University & $12(30)$ \\
\hline Postgraduate & $2(5)$ \\
\hline \multicolumn{2}{|l|}{ Area of residence } \\
\hline Urban & $20(50)$ \\
\hline Rural & $20(50)$ \\
\hline \multicolumn{2}{|l|}{ Smoking status } \\
\hline Smoker & $6(15)$ \\
\hline Ex-smoker & $4(10)$ \\
\hline Non-smoker & $30(75)$ \\
\hline \multicolumn{2}{|l|}{ Body mass index $\left(\mathrm{kg} / \mathbf{m}^{2}\right)$} \\
\hline Mean (SD) & $34.0(5.8)$ \\
\hline $18.5-24.9$ & $3(7.5)$ \\
\hline $25-29.9$ & $4(10)$ \\
\hline $30-39.9$ & $27(67.5)$ \\
\hline$\geq 40$ & $6(15)$ \\
\hline \multicolumn{2}{|l|}{ HbAlc } \\
\hline$<7 \%$ & $19(47.5)$ \\
\hline$\geq 7 \%$ & $21(52.5)$ \\
\hline
\end{tabular}

(Continued)
Table 2 (Continued).

\begin{tabular}{|l|l|}
\hline Variables & $\begin{array}{l}\text { Summary statistics } \\
\text { N (\%) }\end{array}$ \\
\hline Duration of diabetes & \\
Mean (SD) & $15.9(8.8)$ \\
I-4 years & $4(10)$ \\
$5-10$ years & $8(20)$ \\
II-20 years & $14(35)$ \\
$>20$ years & $14(35)$ \\
\hline Number of anti-diabetic and diabetes- & \\
related medications (e.g. aspirin, statin) & \\
Mean (SD) & $5.8(2.7)$ \\
$\leq 4$ medications & $19(47.5)$ \\
$>4$ medications & $21(52.5)$ \\
\hline Anti-diabetic regimen & \\
Oral hypoglycaemic agents & $9(22.5)$ \\
Insulin & $12(30)$ \\
Oral hypoglycaemic agents plus insulin & $19(47.5)$ \\
\hline
\end{tabular}

Abbreviation: SD, standard deviation.

sample of 25 physicians was selected using stratified and random sampling. The stratification of the sample was at the level of the five healthcare regions of Kuwait (Table 3). Five primary care centres that provide outpatient diabetes clinics were selected randomly from each healthcare region; a total of 25 clinics. From the approached 25 physicians, 21 agreed to participate (Table 4 shows the characteristics of the participants), and four physicians refused due to time constraints (response rate $100 \%$; participation rate $84 \%$ ). Physicians were approached by the second author while they were working in their clinics and were invited to participate. Those agreeing to participate were either interviewed at around the same time if they were available or at a later date/time by appointment. All the interviews were completed at the primary care clinic where the physician was working. The duration of the physicians' interviews was 35 to 85 mins.

Table 3 Polyclinics with diabetes care through the five healthcare regions. $^{7}$

\begin{tabular}{|l|l|}
\hline Healthcare region & $\begin{array}{l}\text { Number of polyclinics } \\
\text { providing diabetes care }\end{array}$ \\
\hline Capital & 17 \\
Hawalli & 8 \\
Ahmadi & 15 \\
Jahra & 7 \\
Farwaniya & 12 \\
Total & $\mathbf{5 9}$ \\
\hline
\end{tabular}


Table 4 Characteristics of the participating physicians $(n=2 I)$

\begin{tabular}{|l|l|}
\hline Sex & 13 \\
\hline Male & 8 \\
\hline Female & II years \\
\hline $\begin{array}{l}\text { Average experience in diabetes } \\
\text { (ranged from I-25 years) }\end{array}$ \\
\hline Speciality & \\
\hline Internal medicine & 7 \\
Family medicine & 6 \\
Endocrinology or diabetes & 5 \\
No postgraduate speciality & 3 \\
\hline Health region & \\
\hline Capital & 5 \\
Hawalli & 3 \\
Ahmadi & 4 \\
Jahra & 4 \\
Farwaniya & 5 \\
\hline
\end{tabular}

In qualitative methods there is no gold standard for calculating the number of people to interview, as the aim is to provide rich description of the participants' perspectives rather than to quantify a phenomenon within a large sample size. ${ }^{17,18}$ However, in practice some researchers suggest $12-26$ interviews, ${ }^{19} 30-50$ interviews $^{20}$ or $20-30$ interviews. $^{21}$ Therefore, the researchers continued interviewing patients and physicians until no new experiences and perspectives were raised. This is called "data saturation", 22 which was achieved with 40 patients and 21 physicians, at which point the data collection was terminated. To ensure reliability of the obtained data, the researchers introduced themselves as researchers who were independent and separate from the healthcare team. The researchers then explained to the participants that the aim of the study was to explore their views and experiences surrounding the role of pharmacists, particularly in improving medication adherence and the support needed from them, in order to improve the care provided. Before commencing the interviews, the participants were given the chance to ask questions and assured that their participation was voluntary and that they could withdraw at any time without giving any explanation. They were also assured that their participation would have no impact on the care they received (for patients) or on their interprofessional relationships (for physicians), as their responses would be anonymous and would not be communicated to a third party. At this point, it was also clarified to the participants that there were no right or wrong answers and that their honest views were the primary interest of the study. The participants were allowed to talk freely and without following the particular sequence of the questions, so topics could be explored according to the issues raised by the participants.

\section{Data analysis}

Data analysis started as soon as the first interview was completed using an inductive content analysis approach. ${ }^{23}$ All the interviews were audio-recorded, and the data were transcribed verbatim. The MAXQDA software, version 12 , was used to assist in the management of the textual data. It allowed flexible collection, organisation and analysis of the content from interviews in Arabic. The verbatim transcripts were then analysed according to the six steps of thematic analysis. ${ }^{24}$ This was done first by open coding and then by refining and grouping codes into categories representing themes emerging from data. ${ }^{25}$ This is one of the inductive approaches, the Framework Method or "thematic framework", a matrix-based method that provides an instinctively systematic analysis of summarised data, which is most commonly used in qualitative data analysis. $^{26,27}$ The matrix output of this approach provided a structure, which helped the researcher to reduce data and analyse it by themes, and allowed comparison between data across cases and within individual ones. ${ }^{27}$

In addition, an iterative approach was considered and a constant comparative analysis was conducted. This was achieved by revising data each time a new theme/subtheme was added. All interviews were revisited after primary coding, and inspected for the relevance of these codes, until no additional themes could be developed (no new issues emerged from data-the saturation level). ${ }^{28}$

To ensure the validity and reliability of coding, the second and third authors, who have particular experience in qualitative research in addition to their competence in Kuwaiti language and culture as native speakers, were involved in the analysis. Such prior experience allowed the researchers to easily create rapport and trust with the research participants, which aided in the data collection process. Fifteen interview transcripts were coded separately and independently by the first, second and third authors. The following formula was used to estimate the intercoder reliability: number of agreements/(number of agreements + number of disagreements). Intercoder reliability was found to be $93.3 \%$ on average. 
To ensure trustworthiness of the data, an analytical triangulation of patient and physician interviews was adopted throughout the research with skilled qualitative researchers, in order to avoid potential biases. ${ }^{29}$ Quotes with rich data describing themes/sub-themes were chosen and agreed by all the research team members. In addition, data were collected by one researcher only for each sample category. For example, the first author collected data from patients, and the second author collected data from physicians, which ensured the consistency of the procedures undertaken. For example, the same order was followed for all the interviews, starting with a brief explaination of the aim of the study, signing the consent form, asking the interview questions, and ending with the concluding question. Careful attention was given by both authors to take notes during and after the interviews and to include them into data analysis.

Data were analysed in Arabic, the language in which they were collected. This was to avoid limitations, as the participants used culturally bound words which, if translated, might affect the meaning. ${ }^{30}$ For publication purposes, the results were then translated into English using the parallel blind technique. This method involves two translators independently translating the results into the target language and comparing the translations, looking for any discrepancies and then agreeing on one version. ${ }^{31}$ Figure 1 summarises the methods used in this study.

\section{Ethical approval}

The study was approved by the Standing Committee for Coordination of Health and Medical Research, $\mathrm{MOH}$, Kuwait. Written informed consent was obtained from all the participants prior to participation.

\section{Results}

A total of 40 adults with type 2 diabetes and 21 physicians agreed to participate and were interviewed. The themes that emerged from the interviews with both the patients and the physicians were pharmacy-related issues against medication adherence and pharmacy-related issues for medication adherence (Figure 2). Within each theme, there were several subthemes; there were also factors within sub-themes.

\section{Theme I - pharmacy-related issues against medication adherence Lack of pharmacist counselling}

All the patients agreed that the pharmacist has a limited role in the management of their disease. The patients clarified that the pharmacist's role is limited to dispensing medications and giving basic instructions on how to use medications, such as the frequency of administration or whether to administer the medication before or after food. Three patients, who used insulin pens, indicated that the pharmacist had explained to them how to use the pen when they first dispensed it:

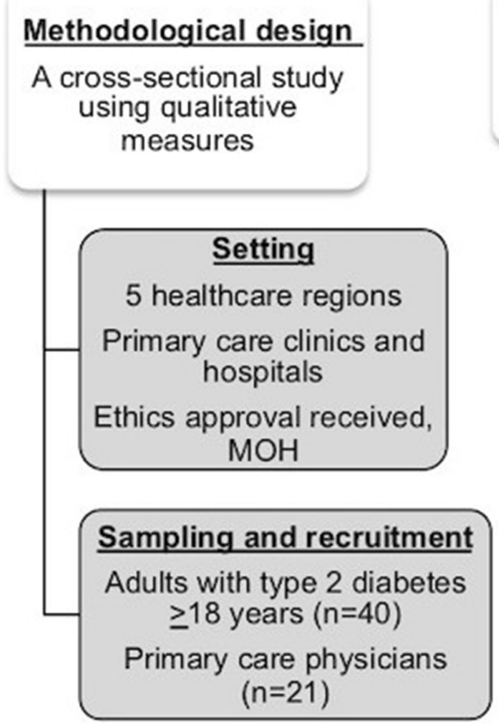

\section{Data colllection}

Semi-structured interviews

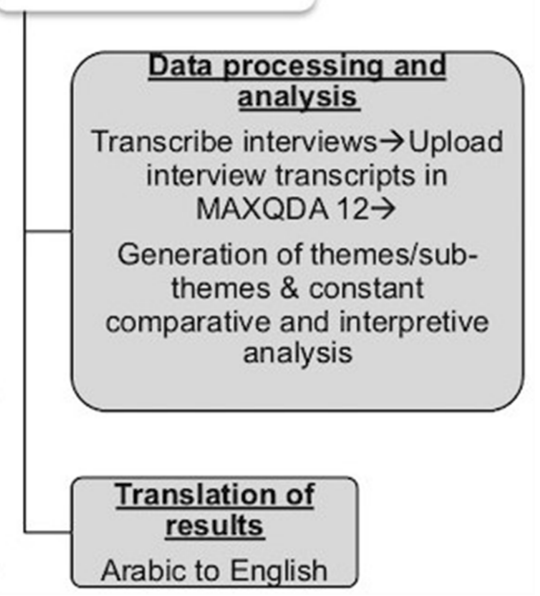

Figure I Methods used in this study. 


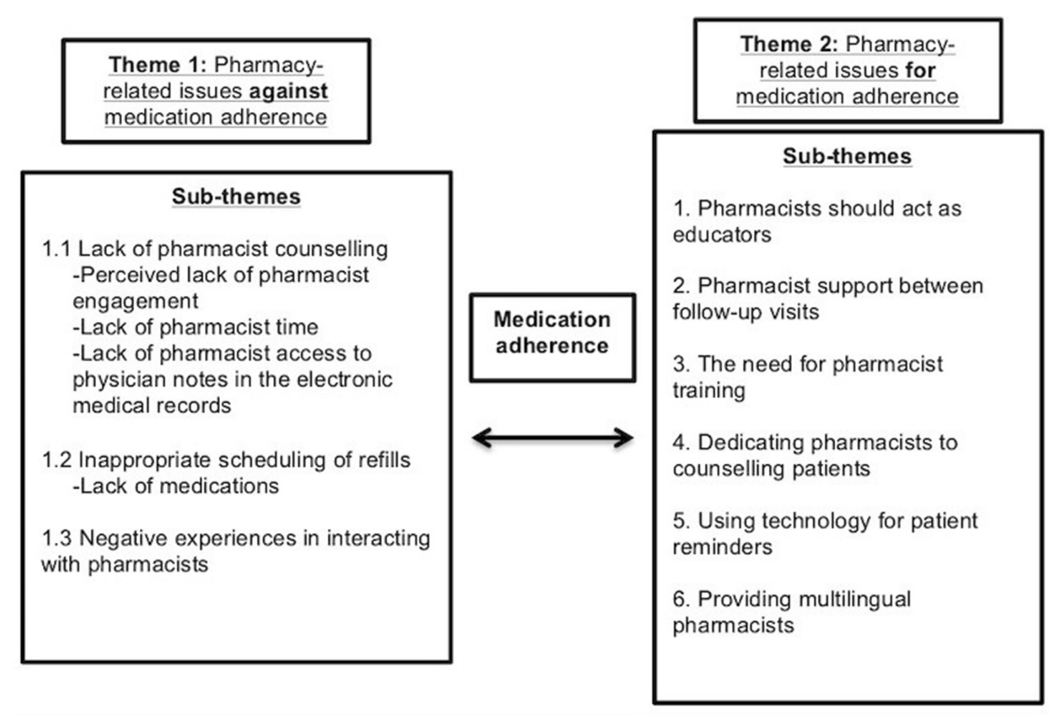

Figure 2 Themes/sub-themes emerging from the interviews with patients and physicians.

The pharmacists only dispense medications. Once, one pharmacist unintentionally noticed that I take more than one medication for my diabetes, Glucophage ${ }^{(\mathbb{R}}$ and Diamicron $^{(\mathbb{R}}$ [metformin $850 \mathrm{mg}$ and gliclazide $120 \mathrm{mg}$ ]. She asked me how I take them and advised me to distribute them over my day, for example, to take Glucophage $^{(\mathbb{B}}$ after breakfast and Diamicron $\left.{ }^{(}\right)$with lunch and dinner, to get better glycaemic control throughout the day. (Patient 8)

The pharmacist only dispenses the medications, says how many times I should take them, whether to take them before or after food and answers questions if I ask them. Once, I had been prescribed a new medication for a cough, and, when I took it, my sugar [blood glucose] had increased. Now, I keep asking the pharmacists each time I receive a new medication whether it has an effect on diabetes or not and they answer me. If I do not ask, they do not mention anything. (Patient 32)

However, all the patients reported that they had learned about their disease and medications from other sources, such as from physicians or nurses:

The doctor is the only helping person in the hospital. Without him, I would feel tired all the time. The pharmacist has no role in my life. They [pharmacists] are like parrots! When dispensing, they just repeat the same instructions to all patients. (Patient 40)

All the interviewed physicians, except two, had negative perceptions about the role of pharmacists in improving patients' medication adherence. The physicians attributed patients' poor adherence to the lack of, or inaccuracy of instructions that they receive from the pharmacists:

Pharmacists have to emphasise adherence to medications.

I met patients who do not know how many times they should take their doses. Sometimes, the patients get confused when the pharmacist dispenses a new brand of their medications or a different strength, e.g. $4 \mathrm{mg}$ instead of 2 $\mathrm{mg}$, and they do not know how to take it. (Physician 15)

Some patients complain that the pharmacists are not writing [on labels of dispensed medication] or explaining how to use the medications. Lots of patients return to me after receiving their prescriptions to explain the instructions to them, while this is the job of the pharmacist! (Physician 16)

Patients always have incorrect information about their medications. For example, I have a patient who used to omit her Lantus $^{\circledR}$ [insulin glargine - a long-acting insulin] dose when she experienced hypoglycaemia because she does not know that Lantus ${ }^{\circledR}$ does not work rapidly. (Physician 17)

Taking this into account, three factors emerged from the analysis of the interviews, which could have contributed to the lack of pharmacist counselling:

\section{(a) Perceived lack of pharmacist engagement}

More than half of the patients $(n=25)$ indicated that pharmacists do not counsel them due to a lack of awareness and knowledge about medications:

The pharmacists only dispense the medications. I do not think that they have a background in medications. Once, I 
asked more than one pharmacist about a medication, when I heard that it had been withdrawn from primary care clinics because of its side effects, but no one had an answer, and one pharmacist said to me, "If you need it, it is still available in the hospital!" (Patient 38)

In this context, six physicians reported the lack of pharmacists' awareness of their responsibilities as a contributing factor to the lack of counselling:

Some pharmacists misunderstand their role, that they should explain to the patients everything about their medications, maybe because this role is underdeveloped in Kuwait. Nurses can help in talking about other management behaviours, such as diet, exercise and how to take care of eyes, feet, etc., but pharmacists, based on their knowledge, can talk about side effects, how to distribute doses during the day and how the medications work. (Physician 9)

(b) Lack of pharmacist time

Fifteen patients reported insufficient time as a factor that contributed to the lack of pharmacist counselling:

When I buy my medications from private pharmacies, the pharmacist explains to me everything. In the government [sector], the pharmacist only throws me the medications bag and that's it. They [pharmacists] do not have the time to answer any queries. (Patient 12)

Half of the physicians $(n=11)$ mentioned that the pharmacist-to-patient ratio is the main problem, as it leads to a lack of pharmacist time. Accordingly, the pharmacists choose to dispense the medications rapidly:

I do not think that pharmacists can have a role in improving patients' awareness and adherence. Pharmacists only dispense the medications and sometimes explain to the patients how to use them. They do not have time, particularly when they have a large number of patients. Sometimes, we see about 50 patients per day while others we see 100. (Physician 7)

Due to the increase in the number of patients, the pharmacists have no time for counselling. They just dispense the medications without explaining any instructions. If the pharmacists explain to the patients how each medication works, how to take it and what possible side effects it has, this will greatly help the patients and also help us [physicians], because we are currently doing this job. (Physician 10)

(c) Lack of pharmacist access to physician notes in the electronic medical records
While this issue was not mentioned by patients, two physicians referred to the Primary Care Information System (PCIS), an electronic system that is used to store patients' medical records and that physicians use to send prescriptions electronically to the pharmacy. The physicians reported that the PCIS should be modified to allow pharmacists access to all the instructions selected by them for a particular patient. Thus, the pharmacist could read all the instructions to the patient, which might help during rush hours:

If all the instructions that we [physicians] select could be printed out on the medication label, this will greatly help the patients and pharmacists. I usually say the instructions to the patient verbally, but if they could be printed out on the label, the pharmacist can just read and explain them in detail to the patient. (Physician 19)

\section{Inappropriate scheduling of refills}

More than a third of the patients $(n=15)$ expressed their frustration with the scheduling of refills, which requires them to visit the pharmacy every month. The patients indicated that they would prefer to refill their prescriptions every two to three months to avoid unnecessarily frequent visits to the hospital and long waiting hours in the pharmacy:

My doctor always prescribes my treatment for two months but the pharmacists do not follow what the doctors write in the prescription ... When I want to collect my prescription, I have to wait for a long time; sometimes it takes three to four hours. (Patient 9)

The pharmacists have a bad role! They always dispense to me fewer pens [insulin pens] ... Sometimes, when I intend to go abroad for a while, I ask them [pharmacists] to process the prescription in full, but they refuse. (Patient 10)

In this context, seven physicians mentioned that, when pharmacists refuse to dispense the medications for more than a one-month period, this could affect the patients' adherence, in particular those patients who go abroad for a long time or who live very far from the clinic and thus cannot attend every month. Some physicians clarified that sometimes pharmacists intentionally avoid dispensing treatment for more than a one-month period to avoid a shortage of medications. The administration office of the $\mathrm{MOH}$ should intervene and solve this problem:

I tried many times with the pharmacy to provide patients with a two-month treatment, even those patients [nonKuwaitis] who pay [the insurance charge]. Sometimes, they want to pay for more than one month to get their 
medications and avoid frequent visits but unfortunately they cannot. This may need a change of policy from the Ministry [MOH]. (Physician 5)

If pharmacists dispense a two-month treatment for patients who live very far from the clinic, this will help them a lot and improve their adherence. Some patients can neither attend every month nor buy their medications from private pharmacies because they are expensive. (Physician 18)

The lack of medications issue was reported by both patients and physicians as a factor that contributed to the inappropriate refilling schedule. The participants indicated that pharmacists always use the lack of medications as an excuse for their refusal to dispense treatments for more than one month:

When I visit my doctor, I always ask him to prescribe my treatment for two months. However, when I go to the pharmacy, they [pharmacists] only give me the medications enough for one month; they say it is unavailable! (Patient 36)

It is really a difficult situation! Medications usually run out from the pharmacy. We [the healthcare team] cannot leave the patient without treatment, particularly if the medication is expensive outside [in private pharmacies]. As they are always available in the private sector, it is essential to provide medications continuously in the governmental sector. (Physician 14)

\section{Negative experiences in interacting with pharmacists} As reported by a quarter of patients $(n=10)$, there were instances in which inappropriate communication with pharmacists had been experienced. For example, patients experienced such situations when they visited the pharmacy on a different day from their prescription refill day, when they asked the pharmacist to dispense extra medications/items or when they asked the pharmacist about particular information:

There should be more care for patients with diabetes. Diabetes makes the patient tired all the time. The sugar [blood glucose level] is either high or low. They [pharmacists] have to know how to talk with patients instead of irritating them. Sometimes, I come to the pharmacy more frequently because I forgot the insulin vial in a hot temperature or it fell and broke. I ask the pharmacists to compensate me but they always become angry and reply inappropriately. (Patient 22)
I hope that the pharmacists will treat patients with diabetes better. Patients with diabetes can easily become angry and their sugar [blood glucose level] could be elevated, and this is very dangerous. When I ask them [pharmacists] questions about my medications, I feel that they neither understand me nor want to explain. (Patient 30)

Pharmacist-physician communication is another aspect of this issue. Nearly one-third of physicians $(n=6)$ illustrated that in some cases, such as prescription errors, the pharmacists explain the information to the patients inappropriately without consulting the prescriber. Accordingly, the patient loses trust in the healthcare professions and chooses not to take the medication:

Sometimes when we [physicians] select the medications from the electronic system, we accidently choose two agents from the same class. When patients receive their prescriptions, the pharmacists tell them that there is an error. This could affect the trust of the patients and accordingly their adherence. Instead, pharmacists can contact the prescriber and discuss the issue so that they can act properly. We [physicians] accept such discussions with pharmacists. (Physician 1)

Once, I prescribed Aldactone ${ }^{\circledR}$ [spironolactone - a potassium-sparing diuretic] to my patient without informing him that it is a diuretic, because I know that he has a phobia of diuretics. Also, in the instructions that we select to send electronically to the pharmacy, I did not choose the name of the class to hide this information from the patient. I just told him that this medication is necessary for patients with diabetes to protect their kidneys. Unfortunately, when the patient dispensed his medication, the pharmacist told him that this is a diuretic. The patient has some beliefs from his friends that taking diuretics will disturb him due to increasing his need to go to the toilet. Thus, the patient did not take the medication. If the pharmacist had discussed that vague information with me first, it would have been better than dealing with the patient in that way. (Physician 13)

\section{Theme 2 - pharmacy-related issues for medication adherence Pharmacists should act as educators}

All the patients expected pharmacists to have an educational role. Although they learned about their disease and medications from their doctors, the patients felt that pharmacists could further improve their health awareness, 
especially during busy times, when doctors do not spend sufficient time with them and answer all their queries:

The doctor is too busy; he has many patients and cannot answer all my questions. I had many questions in my mind about my treatment but I could not ask him because I felt he was in a hurry. If pharmacists would help us [patients], that would be great. (Patient 35)

The doctor explained to me about the disease and its complications, and he is the only person who follows my [blood glucose] readings and adjusts my [insulin] doses accordingly. However, sometimes, the doctor has many patients and only sees me very briefly. I hope that we [patients] can see other [healthcare] professionals, such as pharmacists, so that each patient can sit with a pharmacist and learn from him/her more comfortably. (Patient 39)

For example, some patients mentioned that they need to know more about their medications, for example how to adjust their doses according to their daily activities and possible interactions, to help them to use their treatment more appropriately:

Pharmacists should explain more about medications, their ingredients, action, how we [patients] can take them and what are the possible interactions. We as patients in Kuwait lack this knowledge. (Patient 8)

Other patients felt that they needed to know more about their disease, how it could affect their life and its possible outcomes:

I feel sad for patients with diabetes in Kuwait; we do not know much about our disease. I have a brother who has diabetes, but he does not take any treatment because he does not want to expose his body to the side effects of the drugs. If he knew more about the complications of diabetes, he would definitely take the treatment. (Patient 26)

In this respect, 16 physicians reported that pharmacists never act as educators, although they thought that pharmacists are the most competent healthcare professionals to educate patients about their medications based on their knowledge:

I think that the pharmacists are the most appropriate persons to explain to the patients about their doses and how to distribute them during the day. We, as physicians, sometimes cannot clarify these things to patients, e.g. times of taking doses, what to do in case of missing doses, when to take medications, e.g. before/after meals. (Physician 6)
There is some information that we, as physicians, cannot clarify to the patients. For example, interactions between macrolides [a class of antibiotics] and statins [lipid-lowering medications]. The pharmacist can explain these things to the patient very well. (Physician 17)

\section{Pharmacist support between follow-up visits}

About one third of the patients $(n=14)$, particularly insulin users, reported that the period between doctor's consultations is too long (three to four months). Accordingly, they need to see another healthcare professional, such as a pharmacist, between these visits to help them to adjust their doses and answer their queries. However, no physician mentioned this issue during the interviews:

My doctor advises me how to use my medication, and how to adjust my [insulin] doses according to my daily activities. However, sometimes, in cases of exams or if I have my period, I have bad control of my sugar [blood glucose level] and I need to consult a professional, such as a pharmacist, to help me during these emergency situations. (Patient 22)

I hope that there is back-up for us [patients] between the doctor visits; every three months is a long period [the time between one doctor's visit and another]. If we [patients] see a pharmacist every month, we will not misuse our medications. (Patient 37)

\section{The need for pharmacist training}

The patients in this study did not mention pharmacists' need for training. However, seven physicians recommended that pharmacists should attend educational and training sessions that help them to update their information and improve their communication skills. Such sessions may also help pharmacists to individualise patient care and recognise the different methods that can be used to motivate each patient and improve his/her adherence to medications. For example, one physician said that some patients, especially the elderly, either cannot read or have impaired vision. Thus, by obtaining such information, pharmacists could print out sheets for patients to take home, including advice/images presented in a simple and attractive manner. Another physician found that some patients intentionally do not adhere to the medication if they believe it to be ineffective. Therefore, pharmacists could improve patients' adherence by enhancing their belief in their medications: 
Pharmacists should go through appropriate training that helps them in communicating with patients and improving their adherence. For example, once, I prescribed Lipanthyl ${ }^{\circledR}$ [fenofibrate - a lipid-lowering medication] to a patient for his high cholesterol. When he went to collect the prescription, the pharmacist told him that this medication is not as effective as Zocor $^{(\mathbb{R}}$ [simvastatin - a lipid-lowering medication]. The patient then returned to me and refused to take Lipanthyl ${ }^{\circledR}$, which I had prescribed. (Physician 2)

\section{Dedicating pharmacists to counselling patients}

This sub-theme did not emerge from the interviews with patients. However, in the interviews with physicians, more than a third $(n=8)$ reported their desire to be able to refer patients to pharmacists. The physicians recommended different approaches to fulfilling this need, such as specifying a room in each pharmacy where pharmacists could counsel patients conveniently, away from the congestion of the dispensing window, or allocating a pharmacist each day to sit at a window specifically for counselling patients:

I usually make two referrals for each patient with diabetes: one for the dentist and the other for vaccination. I think we [physicians] could make a third referral to particular pharmacists at a window or in clinics so that they can talk with the patients, educate them about their medications, e.g. how to inject insulin, and discuss what might annoy them in their treatment. Neither we [physicians] nor nurses can explore such issues with patients. (Physician 11)

Another suggestion was to have a pharmacist attending the clinic with each doctor, so that the patients can sit with the pharmacists after meeting the physician and discuss their treatments with them. Physicians even recommended delegating some tasks to pharmacy technicians, such as dispensing prescriptions, liberating pharmacists from performing such tasks to allow them more time for counselling:

The pharmacists do not counsel patients unless the patients ask them questions. I suggested that the pharmacy technicians process prescriptions so that pharmacists would have time to counsel each patient for at least 10 minutes. This would be great! (Physician 20)

\section{Using technology for patient reminders}

Nearly half of the patients $(n=19)$ said that pharmacists' use of technology to remind them about their prescription refill or about their new medications and their doses is an excellent service, which they need. Some patients added that this service is of particular importance to elderly people and those who cannot read and write:

If pharmacists could call patients regularly or send WhatsApp this would be great, especially for old people who need more care and more reminders about their treatments. (Patient 17)

Regarding this concern, two physicians reported that pharmacists could improve patients' adherence by using technology. The physicians suggested sending messages to patients' mobile phones, reminding them about filling their prescriptions and about other management behaviours, such as vaccination and annual tests for feet, eyes and proteinuria:

Pharmacists are the most appropriate persons to do this job [improving patients adherence]. I suggest that pharmacists use the technology to remind patients about their appointments. Particularly, they should target mothers, because, due to their responsibilities, they usually forget about their appointments and treatment. (Physician 8)

\section{Providing multilingual pharmacists}

While no patient mentioned this sub-theme during the interviews, only two physicians indicated that there is a need to employ pharmacists who can speak languages other than Arabic and English to communicate with patients who do not speak either of these languages. The physicians added that patients' adherence could be affected when they do not understand the instructions:

Some patients, such as Indians, cannot speak Arabic or English. If there are pharmacists who can speak their language, this will help in communicating with them and explaining the instructions appropriately. (Physician 4)

\section{Discussion}

To our knowledge, this study is the first in Kuwait to incorporate both patients' and physicians' views surrounding the pharmacist's role in improving medication adherence in type 2 diabetes. The study sheds light on patients' and physicians' expectations and perceptions regarding the role of pharmacists. It also highlights important findings regarding methods that could facilitate pharmacist care and counselling. In this study, the participants identified several barriers to medication adherence that are related to pharmacy practice and the pharmacist's role, and provided suggestions to overcome these barriers. The lack of 
pharmacist counselling and refilling and communication problems were the major barriers.

Counselling is an important tool that pharmacists can use to optimise patient medication adherence and minimise adverse reactions. ${ }^{32}$ The American Society of Health System Pharmacists (ASHP) defines counselling as

providing verbal or written information about medications to the patient or his/her caregiver. It also includes providing proper directions of use, advice on side effects, storage, diet and lifestyle modifications. ${ }^{33}$

Considerable evidence from the United States (US) indicates that when pharmacists were involved in diabetes care through education and counselling, they contributed to improved patients outcomes including $\mathrm{HbA} 1 \mathrm{c}$, medication adherence and quality of life. ${ }^{34}$ Good collaboration between pharmacists and physicians is crucial to improving patients' outcomes in diabetes. ${ }^{35}$

\section{Pharmacist counselling and image The perspectives of patients and physicians}

This study revealed that among the healthcare professionals encountered by patients, physicians and nurses are the main sources of information about type 2 diabetes and its medications. There was an overwhelming consensus among the participants that the pharmacist's role is limited to dispensing medications and sometimes clarifying basic instructions on their administration. This role was met with dissatisfaction from both patients and physicians, who desired a more advanced role. All the participants emphasised the importance of promoting pharmacists' educational role through counselling. These results are consistent with previous data from Kuwait and elsewhere. ${ }^{36-38}$ In those studies, patients reported that the pharmacist's role is restricted to dispensing medications, providing little advice about the dosage. On the other hand, studies in Europe, the United Arab Emirates (UAE), Iraq and Jordan have shown contradicting results, in which the patients were satisfied with the pharmacy services provided, and agreed that pharmacists are the primary source of information about medications. ${ }^{39,40}$ However, those studies reported patients' perspectives about community pharmacists. Therefore, role discrepancies between community pharmacists and pharmacists from other healthcare systems, and the fact that community pharmacies are more business-oriented than patientoriented should be taken into consideration.
Surprisingly, although counselling services delivered by pharmacists have been recommended, most patients in the United Kingdom (UK) and the Middle East see physicians as the top of the healthcare hierarchy. ${ }^{40,41}$ In the current study, some participants lacked confidence in pharmacists and perceived them as medication suppliers only, because they felt that pharmacists lack knowledge of medications. Similarly, research in the UK, the UAE, Australia, Malaysia, Qatar and Iraq has shown that patients and physicians lack trust in pharmacists' knowledge and see them as dispensers only with limited authority. ${ }^{37,41-47}$ Physicians in the UK and Northern Ireland also believe that pharmacists are unaware of advanced clinical services such as the New Medicine Service, which is aimed at patients who have recently been diagnosed with a longterm condition such as type 2 diabetes and focuses on improving their medication adherence to enhance health outcomes. ${ }^{48,49}$ On the other hand, patients, physicians and nurses from Canada, Cuba and Saudi Arabia see pharmacists as experts, counsellors and a trusted source of medication information. ${ }^{5,50-53}$

\section{The perspectives of pharmacists}

When pharmacists from Kuwait were invited to provide their perspectives about counselling patients with diabetes, they reported that they usually counsel patients about the administration of medications but do not progress to more comprehensive counselling about the whole medication profile or the management of diabetic complications such as hypoglycaemia. ${ }^{14}$ Community pharmacists in Kuwait reported that they most frequently help patients on their medication use, which means that patients visiting polyclinics/hospitals may not receive enough information on the use of their medications. ${ }^{54}$ Likewise, data from Saudi Arabia have shown that pharmacists' counselling skills are evaluated as fair or poor with many elements of counselling, such as identification information and checking for medication adherence, being missed. ${ }^{55}$ In the US, pharmacists have also identified that they infrequently provide diabetes patient education, ${ }^{56}$ while pharmacists in Canada and Scotland reported that they consistently provide diabetes-related management activities through counselling such as education in diabetes medication therapy and management of hypoglycaemia. ${ }^{57,58}$

The perspectives of pharmacists are compatible with the perspectives of patients and physicians in this study, who do not acknowledge the knowledge and skills of pharmacists. In 2014 and 2017, 250 and 198 pharmacists 
respectively from Kuwait reported frustration abut their poor image in the eyes of physicians and patients, who see them as dispensers only. ${ }^{13,14}$ Pharmacists in Malaysia perceived a lack of trust from patients and physicians in their abilities to provide healthcare services. ${ }^{59}$ In Nigeria, a survey of 1005 pharmacists revealed that the majority believe that the implementation of pharmaceutical care would improve patients' appreciation of pharmacists. ${ }^{60} \mathrm{In}$ Northern Ireland, pharmacists perceive a lack of physicians' appreciation of their role in healthcare, who see them as shopkeepers. ${ }^{48}$

\section{Lack of time and refilling problems The perspectives of patients and physicians}

Consistent with previous research, pharmacists' lack of time was among the top barriers that hinder the implementation of pharmaceutical care from the perspectives of patients and physicians. ${ }^{8,37,38}$ In the current study, both patients and physicians considered lack of time as a barrier that prevents pharmacists from counselling. Therefore, some participants recommended delegating dispensing to technicians, freeing up pharmacists to deliver more patient-centred care.

There was a new finding in this study that may hinder medication adherence, which was the dissatisfaction with the schedule of refills. Both physicians and patients who reported that issue mentioned the difficulty in visiting the pharmacy every month, and suggested that it would be more convenient to refill every two to three months, due to long waiting hours or because of living far from the hospital/polyclinic. However, in Kuwaiti governmental health settings, medications are dispensed free of charge to Kuwaiti patients and with a minimal charge for nonKuwaiti people. Thus, dispensing a lot at once could result in a shortage. Thereby, pharmacists usually choose to process prescriptions to each patient for a one-month period. This is a logistical problem that must be dealt with the $\mathrm{MOH}$ by increasing the amount of medications delivered to each pharmacy from the Medical Stores.

\section{The perspectives of pharmacists}

A "Lack of time" barrier has been frequently mentioned in pharmacy practice research, from the perspectives not only of patients and physicians but also of pharmacists. In Kuwait, a number of studies conducted since 2006 have shown that pharmacists perceive the lack of time and staff as a barrier to counselling and providing a more educational role for patients. ${ }^{8,13,54,61,62}$ In Qatar, pharmacists have also related their lack of counselling to heavy workloads and lack of time. ${ }^{63}$ Pharmacists in New Zealand and European countries have stated that insufficient time is a barrier to pharmaceutical care implementation. ${ }^{64,65}$

\section{Communication problems}

The perspectives of patients and physicians

Negative experiences in interacting with pharmacists were mentioned by both patients and physicians. Patients in the current study reported negative experiences that discourage them from consulting pharmacists regarding any medical queries. In accordance with a study conducted in the UAE, most patients felt from their interactions with pharmacists that they were discouraged from asking questions. ${ }^{66}$ Contrastingly, patients in Australia reported that friendliness and convenience in their relationship with pharmacists helped to establish diabetes self-management pharmacy services. Good communication improves patients' experiences of and perspectives on pharmacy services. ${ }^{37}$

Physicians in this study and in previous studies reported their readiness to discuss medication-related issues with pharmacists, such as detecting medication errors. ${ }^{42,44}$ They also felt that pharmacists' involvement in the care process would help to reduce their workload and improve patients' outcomes. ${ }^{8}$ Unfortunately, physicians added that pharmacists are uncooperative, avoid such discussions and, in some instances, had informed patients about errors without notifying them first. It was unclear why the pharmacists had responded in that way, because this was not investigated in the current study. However, the situation varies in the US, where studies have shown that physicians are unwilling to collaborate with pharmacists in providing direct patient care, because physicians do not have an accurate understanding of the pharmacists' education and abilities, and due to physicians' beliefs in their own high-level competency and that they are the only professionals who can provide medication therapy management to patients. ${ }^{67,68}$ Physicians in Iraq have also reported their lack of belief in pharmacists' competency, meaning they do not interact with them frequently. ${ }^{46}$ Regular contact between pharmacists and physicians is important to enhance physicians' acceptance of pharmacists' clinical role.

\section{The perspectives of pharmacists}

Research obtaining pharmacists' perspectives on the communication issues has revealed that pharmacists have mixed feelings about inter-professional interactions with 
physicians. They reported that some physicians are open to discussions, while others infrequently contact them regarding medication information. Pharmacists emphasised the need to improve these relationships in order to expand pharmaceutical diabetes care. ${ }^{13,61,62}$ However, pharmacists have also reported that they need special training in behavioural and communication skills to improve their confidence in discussing pharmaceutical care issues with physicians and providing diabetes-related services to patients. $^{13,14,56,61}$

\section{Recommendations for pharmacists to improve patients' medication adherence}

Some of the top suggestions made by the participants in this study were that pharmacists should act as educators, should follow up patients between their doctors' visits, and should dedicate pharmacists to counselling patients.

\section{Pharmacists' educational role}

The perspectives of patients and physicians

Taking the role of an educator and counsellor requires a private area where the pharmacist can discuss private issues with patients confidentially. Although patients in this research did not mention that issue, lack of facilities has been found to be a barrier to the provision of pharmaceutical care and counselling from the perspectives of patients in Australia, Kuwait, Jordan, the UAE and Iraq. ${ }^{37,38,40}$ However, some physicians in the current study who recommended augmenting the pharmacist's educational role suggested allocating a room in the pharmacy for this purpose, designating one window for dispensing and another for education and counselling, or dedicating one pharmacist to work in each doctor's clinic. Bridging the location gap could also improve the pharmacist-physician relationship and promote their collaboration. ${ }^{68}$

Although pharmacists' educational role has been highly recommended, participants in the current study affirmed that pharmacists need appropriate training to enable them to undertake an educational role. However, while the introduction of courses such as the PharmD programme in a number of Middle Eastern countries is a positive step towards improving pharmacists' knowledge, continuous educational training is pivotal. ${ }^{69}$ Physicians in Kuwait perceive lack of pharmacists' clinical skills as a barrier to providing clinical pharmacy services. ${ }^{8}$ Another suggestion provided by the participants in this study was that pharmacists use technology to remind patients about their treatment regimens and follow-up visits. In a review of studies about the effectiveness of mobile phone text messages in the management of chronic diseases, it was proven that they contributed to improved medication adherence and health outcomes. ${ }^{70}$ However, such applications need organisational and financial support from the $\mathrm{MOH}$.

\section{The perspectives of pharmacists}

Pharmacists in Kuwait, New Zealand and Nigeria considered lack of private counselling areas as a major barrier to providing education and counselling to patients. ${ }^{13,60,62,64}$ The need to improve pharmacists' therapeutic skills and knowledge of pharmacotherapy has also been mentioned repeatedly by pharmacists. Although they showed positive attitudes towards diabetes management, pharmacists from the US, Canada, New Zealand, Nigeria, Kuwait and Jordan indicated that they need special training in patient education, because they feel unconfident about undertaking new pharmaceutical care responsibilities, such as medicationrelated care issues and the importance of tight glycaemic control. ${ }^{8,13,14,56,60-62,64,71,72}$ In Ethiopia, the majority of pharmacists stated that they lack knowledge and up-todate information on medications. ${ }^{73}$ Even pharmacists who offered diabetes-related services to patients said that further training and education were required to further develop services. ${ }^{58}$ Regarding the use of technology to improve mediation adherence, pharmacists in Kuwait reported their readiness to enhance application of health technology in healthcare systems. ${ }^{62}$

\section{Strengths and limitations}

This study explored various role perceptions (held by patients and physicians) that are likely to result in advancing healthcare provision for the management of type 2 diabetes and informing service development. In general, this study fills a significant gap in the literature and provides valuable findings relating to policy in the field of pharmacy practice and patient adherence. Unlike previous studies, which provided data from one healthcare region only ${ }^{14}$ or included only pharmacists who were members of the Kuwait Pharmaceutical Association, ${ }^{13}$ this study provided data from both the primary and secondary healthcare levels. Approaching the main five health regions in Kuwait ensured the generalisability of the results by allowing the collection of data from different socio-cultural backgrounds and geographical areas (eg rural and urban), which ensured the coverage of different perspectives and experiences. 
The main limitation of the current study is that the participants, particularly patients, might have confused pharmacists and pharmacy technicians when responding to the questions, as there is no obvious way to differentiate between them. However, this was minimised by collecting data from patients visiting hospitals, in which most dispensing processes are allocated to pharmacists. In addition, the results of this study may not represent the situation in the private sector. Also, it would be more valuable if the adherence level of the participating patients had been evaluated, using a validated tool. This could inspire a different approach to data analysis, where the perspectives of adherents could be contrasted with those of non-adherents, to examine whether the adherence level has an impact on the patients' perspectives. One more limitation of this study is the cross-sectional nature of the data, which limits the responses to one point in time and does not reflect changes in the participants' perspectives over time.

\section{Implications for practice}

The results of this study can positively influence pharmaceutical care in the Middle East. A greater insight into the perceptions explored will help health authorities to plan appropriate strategies to improve pharmaceutical care and develop a pharmacy diabetes care model. Implementing pharmaceutical care in type 2 diabetes has had positive clinical, humanistic and economic outcomes in the short and long terms. ${ }^{74,75}$ Now, models are needed for counselling which are consistent, feasible and evidence-based, like the Asheville project, ${ }^{74}$ so pharmacists can follow such models in different healthcare settings. Pharmacists' passion to provide diabetes services in Kuwait has already been proven; ${ }^{13,62}$ the need now is to work on the other aspects that aid the implementation of pharmaceutical care, such as designing legislation or pharmaceutical policy, inter-professional collaboration and patient acceptance. $^{75}$

In addition, the results of this study can help in emphasising the importance of continuous training and education for pharmacists to improve their knowledge and communication skills. Policy-makers in the $\mathrm{MOH}$ could arrange regular workshops for pharmacists and make them compulsory by including them in annual staff evaluations and requirements. Due to the lack of educators in Kuwait and a number of other Middle Eastern countries, pharmacists are uniquely positioned to undertake a broader patient care role based on their qualifications, accessibility and experience.

\section{Conclusion}

Pharmacists in Kuwait have a minimal role in the management of type 2 diabetes. This study revealed different pharmacyrelated issues that could affect patients' adherence to treatment. If pharmacists become aware of and improve those issues, this will help patients to better understand their treatment and accordingly improve their adherence. However, many factors that limit pharmacists from practising their role efficiently were identified, and recommendations for healthcare provision and service development were addressed. Policy-makers should be aware of the importance of involving and supporting pharmacists in the management of such a fast-growing disease in Kuwait, in order to improve health outcomes.

\section{Acknowledgment}

The authors would like to thank all patients and physicians who took part in this study. Without their cooperation, this research would not have been possible.

\section{Disclosure}

The authors confirm that they have no conflicts of interest to declare in this work.

\section{References}

1. IDF Diabetes Atlas, Sixth Edition. International Diabetes Federation (IDF); 2013. Available from: http://www.idf.org/diabetesatlas. Accessed June 2, 2018.

2. Alhowaish AK. Economic costs of diabetes in Saudi Arabia. J Family Community Med. 2013;20(1):1-7. doi:10.4103/2230-8229.108174

3. Alsairafi $Z$ Use of medicines and devices by adults for the management of type 2 diabetes in Kuwait [doctoral thesis]. London: University College London; 2016.

4. Badawi D, Saleh S, Natafgi N, Mourad Y, Behbehani K. Quality of type II diabetes care in primary health care centres in Kuwait: employment of a Diabetes Quality Indicator Set (DQIS). PLoS One. 2015;10(7):1-12. doi:10.1371/journal.pone.0132883

5. Varela N, Oliveira D, Argilagos C, et al. What is the role of the pharmacist? Physicians' and nurses' perceptions in community and hospital settings of Santiago de Cuba. Braz J Pharm Sci. 2011;47 (4):709-718. doi:10.1590/S1984-82502011000400007

6. Anaya J, Rivera J, Lawson K, Garcia J, Luna J, Ortiz M. Evaluation of pharmacist-managed diabetes mellitus under a collaboration drug therapy agreement. Am J Health Syst Pharm. 2008;65(19):18411845. doi:10.2146/ajhp070087

7. Ministry of Health (MOH). 2014. Annual Health Report. Department of Health Information and Medical Records. Ministry of Health Kuwait.

8. Lemay J, Wahidi M, Al-Taweel D, Bayoud T, Moreau P. Clinical pharmacy in Kuwait: services provided, perceptions and barriers. Saudi Pharm J. 2018;26(4):481-486. doi:10.1016/j.jsps.2018.02.011

9. Jeragh-Alhaddad FB, Waheedi M, Barber ND, Brock TP. Barriers to medication taking among Kuwaiti patients with type 2 diabetes: a qualitative study. Patient Prefer Adherence. 2015;23(9):1491-1503. doi:10.2147/PPA.S86719

10. Mechanic D. Public trust and initiatives for new health care partnership. Milbank Q. 1998;76:281-302. doi:10.1111/1468-0009.00089 
11. Alhyas L, Nielsen JD, Dawoud D, Majeed A. Factors affecting the motivation of healthcare professional providing care to Emiratis with type 2 diabetes. $J$ R Soc Med. 2013;4(14):1-13.

12. Statistical Review, ed 36. State of Kuwait: general statistics Bureau; 2013. Available from: https://www.e.gov.kw/sites/kgoenglish/Forms/ StatisticalReview-2013.pdf. Accessed July 30, 2018.

13. Al-Taweel D, Awad AI, Johnson BJ. Pharmacists' contribution to the delivery of pharmaceutical care to patients with type 2 diabetes in Kuwait. Int J Diabetes Dev Ctries. 2014;34(2):108-115. doi:10.1007/s13410-0130169-4

14. Al Haqan A, Al-Taweel D, Awad A, Wake D. Pharmacists' attitudes and role in diabetes management in Kuwait. Med Princ Pract. 2017;26:273-279. doi:10.1159/000456088

15. Althubaiti A. Information bias in health research: definition, pitfalls, and adjustment methods. J Multdiscip Healthcare. 2016;9:211-217. doi:10.2147/JMDH.S104807

16. Pope C, Mays N. Qualitative Research in Health Care. UK: WileyBlackwell; 2007.

17. Corbin J, Strauss A. Basics of Qualitative Research: Techniques and Procedures for Developing Grounded Theory. Thousand Oaks: SAGE Inc; 2008.

18. O'Reilly M, Parker N. 'Unsatisfactory Saturation': a critical exploration of the notion of saturated sample sizes in qualitative research. Qual Res. 2013;13(2):190-197. doi:10.1177/1468794112446106

19. Luborsky M, Rubinstein R. Sampling in qualitative research: rationale, issues, and methods. PMC. 1995;17(1):89-113.

20. Morse J. Handbook of Qualitative Research: Designing Funded Qualitative Research. Thousand Oaks: SAGE Inc; 1994.

21. Creswell JW. Qualitative Inquiry and Research Design: Choosing among Five Traditions. Thousand Oaks: SAGE Inc; 1998.

22. Glaser B, Strauss A. The Discovery of Grounded Theory. Strategies for Qualitative Research. Piscataway, New Jersey: Transaction; 1967.

23. Burnard P, Gill P, Stewart K, Treasure E, Chadwick B. Analysing and presenting qualitative data. $B r$ Dent $J . \quad$ 2008;204:429-432. doi:10.1038/sj.bdj.2008.292

24. Braun V, Clarke V. Using thematic analysis in psychology. Qual Res Psychol. 2006;3(2):77-101. doi:10.1191/1478088706qp063oa

25. Ritchie J, Spencer L. Analyzing Qualitative Data. London, UK: Routledge; 1994.

26. Smith J, Firth J. Qualitative data analysis: the framework approach. Int J Res Meth Nurs Health Care. 2011;18(2):52-62.

27. Gale NK, Heath G, Cameron E, Rashid S, Redwood S. Using the framework method for the analysis of qualitative data in multi-disciplinary health research. BMC Medic Res Meth. 2013;13:117. doi:10.1186/1471-2288-13-117

28. Smith F. Analysis of data from focus groups: group interaction-the added dimension. Int J Pharm Pract. 1999;7:192-196. doi:10.1111/ j.2042-7174.1999.tb00968.x

29. Hadi MA, José Closs S. Ensuring rigour and trustworthiness of qualitative research in clinical pharmacy. Int J Clin Pharm. 2016;38(3):641-646.

30. van Nes F, Abma T, Jonsson H, Deeg D. Language differences in qualitative research: is meaning lost in translation? Eur J Ageing. 2010;7(4):313-316. doi:10.1007/s10433-010-0168-y

31. Hambleton RK, Patsula L. Adapting tests for use in multiple languages and cultures. Soc Indic Res. 1998;45(1):153-171. doi:10.1023/A:1006941729637

32. Ansari J. Drug interaction and pharmacist. J Young Pharm. 2010;2 (3):326-331. doi:10.4103/0975-1483.66807

33. American Society of Health-System Pharmacists ASHP. Guidelines on pharmacist-conducted patient education and counselling. Am J Health-Syst Pharm. 1997;54:431-434. doi:10.1093/ajhp/54.4.431

34. Armor B, Britton M, Dennis V, Letassy N. A review of pharmacist contributions to diabetes care in the United States. Int J Pharm Pract. 2010;23(3):250-64. doi:10.1177/0897190009336668
35. Wallgren S, Berry-Caban C, Bowers L. Impact of clinical pharmacist intervention on diabetes-related outcomes in a military treatment facility. Ann Pharmacother. 2012;46(3):317-328. doi:10.1345/aph.1Q564

36. Svarstad B, Mount J, Tabak E. Expert and consumer evaluation of patient medication leaflets provided in U.S. pharmacies. $J$ Am Pharm Assoc. 2005;45(4):443-451. doi:10.1331/1544345054475586

37. Dhippayom T, Krass I. Supporting self-management of type 2 diabetes: is there a role for the community pharmacist? Patient Prefer Adherence. 2015;9:1085-1092. doi:10.2147/PPA.S82441

38. Awad A, Al-Rasheedi A, Lemay J. Public perceptions, expectations, and views of community pharmacy practice in Kuwait. Med Princ Pract. 2017;26:438-446. doi:10.1159/000481662

39. Catic T, Jusufovic F, Tabakovic V. Patients' perception of community pharmacist in Bosnia and Herzegovina. Mater Sociomed. 2013;25 (3):206-209. doi:10.5455/msm.

40. Basheti I, Qunaibi E, Hamadi S, et al. Patient perspectives of the role of the community pharmacist in the middle east: Jordan, United Arab Emirates and Iraq. Pharmacol Pharm. 2014;5:588-599. doi:10.4236/ pp. 2014.56069

41. Hindi A, Schafheutle E, Jacobs S. Patient and public perspectives of community pharmacies in the United Kingdom: a systematic review. Health Expect. 2018;21(2):409-428. doi:10.1111/hex.2018.21.issue-2

42. Azhar S, Hassali M, Ibrahim M. Doctors' perception and expectations of the role of the pharmacist in Punjab, Pakistan. Trop J Pharm Res. 2010;9(3):205-222. doi:10.4314/tjpr.v9i3.56279

43. El Hajj M, Al-Saeed H, Khaja M. Qatar pharmacists' understanding, attitudes, practice and perceived barriers related to providing pharmaceutical care. Int J Clin Pharm. 2016;38(2):330-343. doi:10.1007/ s11096-016-0246-0

44. Zaidan M, Singh R, Wazaify M, Tahaineh L. Physicians' perceptions, expectations, and experience with pharmacists at Hamad Medical Corporation in Qatar. $J$ Multidiscip Healthc. 2011;4:85-90. doi:10.2147/JMDH.S14326

45. Wilbur K, Beniles A, Hammuda A. Physician perceptions of pharmacist roles in a primary care setting in Qatar. Global Health. 2012;8 (12):1-4. doi:10.1186/1744-8603-8-12

46. Hamadi S, Mahmoud M, Dizaye K, Basheti I. Perceptions, experiences and expectations of physicians regarding the role of the pharmacist in an Iraqi hospital setting. Trop J Pharm Res. 2015;14 (2):293-301. doi:10.4314/tjpr.v14i2.15

47. Rayes I, Abdulkarem A. A qualitative study exploring physicians' perceptions on the role of community pharmacists in Dubai. Pharm Pract (Granada). 2016;14(3):738-742. doi:10.18549/PharmPract.2016.03.738

48. Hughes C, McCann S. Perceived interprofessional barriers between community pharmacists and general practitioners: a qualitative assessment. Br J Gen Pract. 2003;53(493):600-606.

49. Latif A, Waring J, Watmough D, et al. Examination of England's New Medicine Service (NMS) of complex health care interventions in community pharmacy. Res Social Adm Pharm. 2016;12(6):966989. doi:10.1016/j.sapharm.2015.08.011

50. Matowe L, Abahussain E, Al-Saffar N, Bihzad S, Al-Foraih A, AlKandery A. Physicians' perceptions and expectations of pharmacists' professional duties in government hospitals in Kuwait. Med Princ Pract. 2006;15:185-189. doi:10.1159/000092179

51. Ibrahim O, Ibrahim R. Perception of physicians to the role of clinical pharmacists in United Arab Emirates (UAE). Pharmacol Pharm. 2014;5(9):895-902. doi:10.4236/pp.2014.59100

52. Kelly D, Young S, Phillips L, Clark D. Patient attitudes regarding the role of the pharmacist and interest in expanded pharmacist services. Can Pharm J (Ott). 2014;147(4):239-247. doi:10.1177/1715163514535731

53. Ahmed N, Abdulghani M, Allrebdi S, Baobaid M. Perceptions of physicians about clinical pharmacist's role in Al Qassinm's Hospitals in Saudi Arabia. Malaysian $J$ Public Health Medi. 2017;17(3):109-116. 
54. Awad A, Abahussain E. Health promotion and education activities of community pharmacists in Kuwait. Pharm World Sci. 2010;32:146153. doi:10.1007/s11096-009-9360-6

55. Alfadl A, Alrasheedy A, Alhassun M. Evaluation of medication counselling practice at community pharmacies in Qassim region, Saudi Arabia Saudi Pharm J. 2018;26:258-262. doi:10.1016/j.jsps.2017.12.002

56. Younis WS, Campbell S, Slack MK. Pharmacists' attitudes toward diabetes and their involvement in diabetes education. Ann Pharmacother. 2001;35:841-845. doi:10.1345/aph.10373

57. Simpson S, Haggarty S, Johnson J, Schindel T, Tsuyuki R, Lewansuzuk R. Survey of pharmacist activities and attitudes in diabetes management. Can Pharm J (Ott). 2009;142(3):1-12.

58. Douglas E, Power A, Hudson S. Pharmaceutical care of the patient with diabetes mellitus: pharmacists' priorities for services and educational needs in Scotland. Int J Pharm Pract. 2010;15(1):47-52. doi:10.1211/ijpp.15.1.0008

59. Saw P, Nissen L, Freeman C, Wong P, Mak V. A qualitative study on pharmacists' perception in integrating pharmacists into private general practitioner's clinics in Malaysia. Pharm Pract (Granada). 2017;15(3):1-8. doi:10.18549/PharmPract.2017.03.971

60. Oparah A, Eferakeya A. Attitudes of Nigerian pharmacists towards pharmaceutical care. Pharm World Sci. 2005;27(3):208-214. doi:10.1007/s11096-004-2268-2

61. Awad A, Al-Ebrahim S, Abahussain E. Pharmaceutical care services in hospitals of Kuwait. J Pharm Pharm Sci. 2006;9(2):149-157.

62. Katoue M, Awad A, Schwinghammer T, Kombian S. Pharmaceutical care in Kuwait: hospital pharmacists' perspectives. Int J Clin Pharm. 2014;36(6):1170-1178. doi:10.1007/s11096-014-0013-z

63. Jaam M, Abdbul Hadi M, Kheir N, et al. A qualitative exploration of barriers to medication adherence among patients with uncontrolled diabetes in Qatar: integrating perpectives of patients and health care providers. Patient Prefer Adherence. 2018;12:2205-2216. doi:10.2147/ PPA.S174652

64. Dunlop J, Shaw J. Community pharmacists' perspectives on pharmaceutical care implementation in New Zealand. Pharm World Sci. 2002;24(6):224-230. doi:10.1023/A:1021526425458
65. van Mil J, de Boer W, Tromp TH. European barriers to the implementation of pharmaceutical care. J Pharm Pract. 2011;9(3):163-168.

66. Al Akshar S, Metwaly Z, Shamssain M. Patients' perceptions of community pharmacy practice in UAE: an overview. IOSR $J$ Pharm. 2014;4(11):8-14.

67. Mcgrath S, Snyder M, Duenas G. Physician perceptions of pharmacistprovided medication therapy management: qualitative analysis. $J \mathrm{Am}$ Pharm Assoc (2003). 2010;50(1):67-71. doi:10.1331/JAPhA.2010.08186

68. Hager K, Uden D, Tomaszewski D. Bridging the location gap: physician perspectives of physician-pharmacist collaboration in patient care (BRIDGE Phase II). J Res Interprof Pract Educ. 2015;5(2):291-298.

69. Kheir N, Zaidan M, Younes H, El Hajj M, Wilber K, Jewesson P. Pharmacy education and practice in 13 middle eastern countries. Am J Pharm Edu. 2008;72(6):133. doi:10.5688/aj7206133

70. Sarabi R, Sadoughi F, Orak R, Bahaadinbeigy K. The effectiveness of mobile phone text messaging in improving medication adherence for patients with chronic diseases: a systematic review. Iran Red Crescent Med J. 2016;18(5):e25183.

71. Schapansky LM, Johnson JA. Pharmacists' attitudes toward diabetes. Am Pharm Assoc. 2000;40(3):371-377.

72. Aburuz S, Al-Ghazawi M, Snyder A. Pharmaceutical care in a community-based practice setting in Jordan: where are we now with our attitudes and perceived barriers? Int J Pharm Pract. 2012;20:71-79. doi:10.1111/j.2042-7174.2011.00165.x

73. Wabe N, Raju N, Angamo M. Knowledge, attitude and practice of patient medication counselling among drug dispensers in North West Ethiopia. J Appl Pharm Sci. 2011;1(7):85-90.

74. Cranor C, Bunting B, Christensen D. The Asheville Project: longterm clinical and economic outcomes of a community pharmacy diabetes care program. J Am Pharm Assoc (Wash). 2003;43(2):173184. doi:10.1331/108658003321480713

75. Hughes J, Wibowo Y, Sunderland B, Hoti K. The role of the pharmacist in the management of type 2 diabetes: current insights and future directions. Integr Pharm Res Pract. 2017;6:15-27. doi:10.2147/IPRP.S103783
Patient Preference and Adherence

\section{Publish your work in this journal}

Patient Preference and Adherence is an international, peer-reviewed, open access journal that focusing on the growing importance of patient preference and adherence throughout the therapeutic continuum. Patient satisfaction, acceptability, quality of life, compliance, persistence and their role in developing new therapeutic modalities and compounds to optimize clinical outcomes for existing disease states are major areas of interest for the journal. This journal has been accepted for indexing on PubMed Central. The manuscript management system is completely online and includes a very quick and fair peer-review system, which is all easy to use. Visit http:// www.dovepress.com/testimonials.php to read real quotes from published authors. 